\title{
BMJ Open Correlation between perioperative parecoxib use and postoperative acute kidney injury in patients undergoing non-cardiac surgery: a retrospective cohort analysis
}

$\overline{\text { Yong-Zhong Tang (10 , }{ }^{1} \text { Pingping Zeng, }{ }^{1} \text { Yan Liao, }{ }^{1} \text { Zheng Qin, }{ }^{2} \text { Hao Zhang, }{ }^{3} \text { Bo Li, }{ }^{4}}$ Wen Ouyang, ${ }^{1}$ Dan Li (D) ${ }^{1}$

To cite: Tang Y-Z, Zeng P, Liao Y, et al. Correlation between perioperative parecoxib use and postoperative acute kidney injury in patients undergoing non-cardiac surgery: a retrospective cohort analysis. BMJ Open 2021;11:e047840. doi:10.1136/ bmjopen-2020-047840

- Prepublication history and additional supplemental material for this paper are available online. To view these files, please visit the journal online. (http://dx.doi.org/10.1136/ bmjopen-2020-047840).

Received 14 December 2020 Accepted 02 August 2021

Check for updates

(c) Author(s) (or their employer(s)) 2021. Re-use permitted under CC BY-NC. No commercial re-use. See rights and permissions. Published by BMJ.

For numbered affiliations see end of article.

Correspondence to

Dr Dan Li;

danfuer623@163.com

\section{ABSTRACT}

Objective The association of non-steroidal antiinflammatory drugs with postoperative acute kidney injury (AKI) is controversial. However, there are few studies focusing on the association between parecoxib and postoperative AKI. Our study aimed at the possible correlation between the intraoperative administration of cyclooxygenase- 2 inhibitors parecoxib and perioperative AKI.

Design A retrospective cohort study.

Setting Third Xiangya Hospital of Central South University in Hunan Province, China.

Participants The electronic medical records and laboratory results were obtained from 9246 adult patients (18-60 years) undergoing non-cardiac surgery performed between 1 January 2012 and 31 August 2017. Study groups were treated with or without parecoxib. Interventions Univariable analysis identified demographic, preoperative laboratory and intraoperative factors associated with AKI. Logistic stepwise regression was used to calculate the adjusted OR of parecoxib and AKI association.

Results The incidence of AKI was lower in the parecoxibadministered group (4\%) than that in the group without parecoxib $(6.3 \%, p=0.005)$. In the multivariable regression analysis, postoperative AKI risk reduced by $39 \%$ (OR 0.61 ; $95 \% \mathrm{Cl} 0.43$ to 0.87 ) in the parecoxib-administered group after adjusting for interference factors. Sensitivity analysis showed that postoperative AKI risk reduced in four subgroups: eGRF <90 mL/min.1.73/m² (OR 0.49; $95 \% \mathrm{Cl}$ 0.29 to 0.82 ), non-smoker (OR $0.55 ; 95 \% \mathrm{Cl} 0.37$ to 0.83 ), blood loss < $1000 \mathrm{~mL}$ (OR 0.55; $95 \% \mathrm{Cl} 0.37$ to 0.83 ) and non-hypotension (OR $0.57 ; 95 \% \mathrm{Cl} 0.38$ to 0.84 ).

Conclusions Thus, parecoxib is associated with a modest reduction of postoperative AKI risk among adult patients undergoing non-cardiac surgery.

\section{BACKGROUND}

Acute kidney injury (AKI), a long-recognised complication of surgery with a high incidence of morbidity and mortality, increases healthcare costs and length of hospital stay. ${ }^{1-3}$ Even

\section{STRENGTHS AND LIMITATIONS OF THIS STUDY}

$\Rightarrow$ Large study population including all adult patients (18-60 years) undergoing non-cardiac surgery in Third Xiangya Hospital of Central South University in China between 2012 and 2017.

$\Rightarrow$ Univariable analysis identified demographic, preoperative laboratory and intraoperative factors associated with acute kidney injury.

$\Rightarrow$ Logistic stepwise regression was used to calculate the adjusted OR of parecoxib and acute kidney injury association.

$\Rightarrow$ The selection bias and some unknown confounders in this retrospective single-centre observational study may limit the generalisability of the results.

in patients undergoing non-cardiac surgery with low-grade American Society of Anesthesiologists (ASA) physical status such as ASA I-II, the incidence of postoperative AKI can reach $6 \% .{ }^{4}$ Mild kidney injury, such as a small increase in postoperative serum creatinine, is associated with renal dysfunction for as long as 1-2 years after surgery. ${ }^{5}$

Non-steroidal anti-inflammatory drugs (NSAIDs) are commonly used perioperative anaesthetic adjuvants, with anti-inflammatory and analgesic effects. The main mechanism of action of NSAIDs is the inhibition of cyclooxygenase (COX) enzymes, which can ultimately result in the reduction of prostanoids and thromboxan. ${ }^{6}$ Within the kidneys, prostaglandins act as vasodilators to ensure adequate flow to the organ. NSAIDs inhibit this mechanism and can lead to AKI. The second form of NSAID-induced AKI is acute interstitial nephritis, which may be related to the prolonged exposure to NSAIDs, and interstitial infiltrates with the predominance of T-lymphocytes. ${ }^{7}$ 


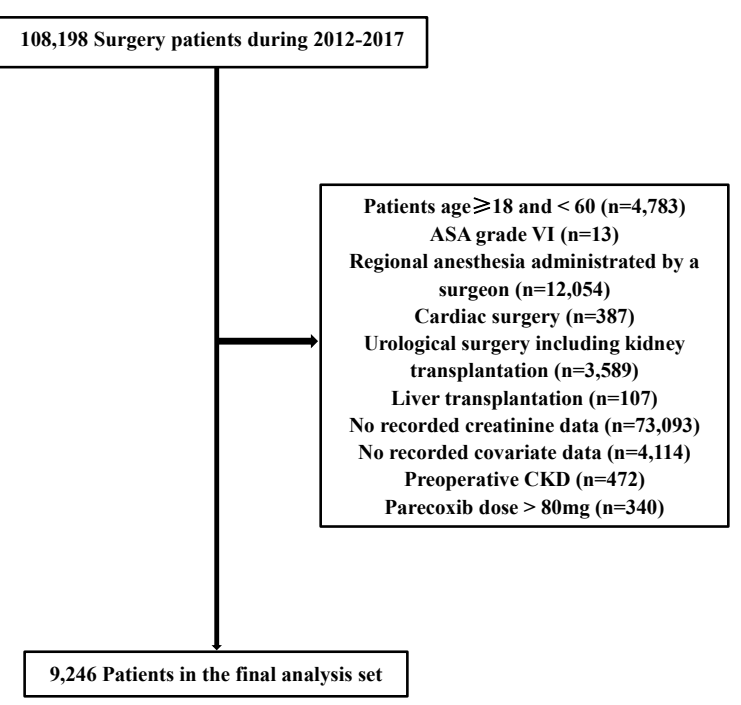

Figure 1 Enrolment of patients undergoing non-cardiac surgery. The numbers in brackets represent patients excluded for the reasons described earlier. ASA, American Society of Anesthesiologists; CKD, chronic kidney disease.

COX exists in two forms: COX-1, which is present in most body tissues body including the stomach, intestines and COX-2, which is primarily found at sites of inflammation. ${ }^{8}$ Accumulating evidence suggests that traditional NSAIDs, such as aspirin and ibuprofen, are associated with acute and chronic gastrointestinal bleeding and kidney disease. ${ }^{9}{ }^{10}$ These NSAIDs are non-selective COX (COX-1 and COX-2) inhibitors and their side effects are mostly COX-1 related.

Parecoxib is a parenteral-specific COX-2 inhibitor, which enhances its therapeutic gain with minimal adverse effects. ${ }^{6}{ }^{11}$ Parecoxib is used as a perioperative analgesic in over 80 countries, however, clinical data about the effect of parecoxib on postoperative AKI are scarce. Therefore, it is important to establish its safety during the perioperative period. The aim of this study was to assess the correlation between the perioperative use of parecoxib and postoperative AKI in patients undergoing noncardiac surgery.

\section{METHODS}

\section{Design and selection criteria}

This retrospective study was performed at the Third Xiangya Hospital of Central South University from 1 January 2012 to 31 August 2017. The inclusion criterion was patients aged 18-60 years who underwent noncardiac surgery. The exclusion criteria were ASA grade VI, regional anaesthesia administrated by a surgeon, liver transplantation, cardiac surgery, urological surgery (including kidney transplantation), lack of serum creatinine or covariate data and preoperative combined chronic kidney disease $(\mathrm{CKD})$, defined as estimate glomerular filtration rate (eGFR) $<60 \mathrm{~mL} / \mathrm{min} / 1.73$ / $\mathrm{m}^{2}, \geq 3$ months). Whether to use the parecoxib or not was based on the doctor's preference. Parecoxib doses larger than $80 \mathrm{mg}$ were not included because the routine dose is not more than $80 \mathrm{mg} /$ day based on the drug instructions.

\section{Data collection}

The following information was collected: (1) epidemiological data including age, sex and body mass index (BMI); (2) individual history including preoperative complications and medication history; (3) laboratory data including serum creatinine and eGFR calculated using the CKD Epidemiology Collaboration formula; (4) intraoperative data including emergency, surgical grade, operative time, anaesthesia method, ASA grade, amount of fluid infusion and out, intraoperative erythrocyte transfusion volume, amount of blood loss, intraoperative hypotension and vasoactive drugs and (5) postoperative outcomes such as the occurrence of AKI, admission to intensive care unit (ICU) and mortality. All clinical data of the 9246 patients who underwent non-cardiac surgery were obtained by a retrospective review of the computerised patient record system of our hospital.

\section{Definitions}

Postoperative AKI was defined according to the Kidney Disease: Improving Global Outcomes 2012 creatinine criteria, ${ }^{12}$ as one of the following: an increase in serum creatinine by $\geq 0.3 \mathrm{mg} / \mathrm{dL}$ within 48 hours or $\mathrm{a} \geq 1.5$ times increase in serum creatinine from baseline within seven postoperative days. The baseline serum creatinine level was calculated using the lowest level within preoperative day 7 . The primary outcome was the impact of parecoxib on AKI, defined as AKI occurring within seven postoperative days. Parecoxib administration was defined during the operative time. The surgical grade was classified using the surgical classification catalogue constituted by the Chinese Ministry of Health, published in 2018. Intraoperative hypotension was defined as mean arterial pressure $<65 \mathrm{~mm} \mathrm{Hg}$ for a duration of at least $5 \mathrm{~min}$.

\section{Patient and public involvement}

No patient involvement.

\section{Statistical analysis}

All statistical analyses were performed using SAS V.9.4 software (SAS Institute) and CRAN R (V.3.4.3). Missing data of covariates (including BMI and eGFR) were handled by a multiple imputation model. The continuous results are expressed as mean (SD), whereas categorical variables are expressed as numbers with percentages. The Kruskal-Wallis rank sum test was used to compare continuous variables between groups, whereas the $\chi^{2}$ test or Fisher's exact probability method was used for categorical variables. Univariable logistic regression analysis was used to identify epidemiological, preoperative laboratory and intraoperative factors that were significantly associated with AKI development. The data were adjusted 
Table 1 Baseline characteristics of patients aged 18-60 years treated with and without parecoxib

\begin{tabular}{|c|c|c|c|}
\hline Clinical features & $\begin{array}{l}\text { Without parecoxib } \\
(n=8273)\end{array}$ & $\begin{array}{l}\text { With parecoxib } \\
(n=973)\end{array}$ & $P$ value \\
\hline Age (year) & $44.23 \pm 10.46$ & $44.89 \pm 10.04$ & 0.06 \\
\hline eGFR & $101.66 \pm 16.66$ & $101.56 \pm 16.23$ & 0.858 \\
\hline Male & $4062(49.1 \%)$ & $508(52.2 \%)$ & 0.063 \\
\hline Smoking & 1175 (14.2\%) & $146(15 \%)$ & 0.479 \\
\hline Anaemia & 1547 (18.7\%) & $152(15.6 \%)$ & 0.019 \\
\hline Hypertension & $1903(23 \%)$ & $189(19.4 \%)$ & 0.011 \\
\hline Diabetes mellitus & 505 (6.1\%) & 56 (5.8\%) & 0.666 \\
\hline ACEI & $199(2.4 \%)$ & $14(1.4 \%)$ & 0.065 \\
\hline ASA grade & & & 0.09 \\
\hline I-II & $6196(74.9 \%)$ & 753 (77.4\%) & \\
\hline III-V & 2077 (25.1\%) & $220(22.6 \%)$ & \\
\hline Anaesthesia method & & & $<0.001$ \\
\hline General anaesthesia & $7363(89 \%)$ & 907 (93.2\%) & \\
\hline Non-general anaesthesia & $910(11 \%)$ & $66(6.8 \%)$ & \\
\hline Emergency & $1406(17 \%)$ & $119(12.2 \%)$ & $<0.001$ \\
\hline Surgical grade & & & $<0.001$ \\
\hline 1 & $240(2.9 \%)$ & $19(2 \%)$ & \\
\hline $121-180$ & $1919(23.2 \%)$ & $246(25.3 \%)$ & \\
\hline$>180$ & $2954(35.7 \%)$ & $435(44.7 \%)$ & \\
\hline Intraoperative erythrocyte transfusion, $\mathrm{mL}(\%)$ & & & 0.94 \\
\hline$<100$ & $6329(76.5 \%)$ & $744(76.5 \%)$ & \\
\hline $100-600$ & $852(10.3 \%)$ & $98(10.1 \%)$ & \\
\hline $601-1000$ & $496(6 \%)$ & $56(5.8 \%)$ & \\
\hline$>1000$ & $596(7.2 \%)$ & $75(7.7 \%)$ & \\
\hline Amount of blood loss, mL (\%) & & & 0.003 \\
\hline$<100$ & 2507 (30.3\%) & $251(25.8 \%)$ & \\
\hline $100-600$ & $4500(4.4 \%)$ & $559(57.5 \%)$ & \\
\hline $601-1000$ & $662(8 \%)$ & $70(7.2 \%)$ & \\
\hline$>1000$ & $604(7.3 \%)$ & $93(9.6 \%)$ & \\
\hline Intraoperative hypotension & 10.8 & 11.9 & 0.297 \\
\hline Vasoactive drugs & 7.8 & 8.9 & 0.227 \\
\hline Amount of fluid infusion (10 mL/24 hours) & $1037.07 \pm 565.54$ & $1159.31 \pm 579.85$ & $<0.001$ \\
\hline $\begin{array}{l}\text { Amount of fluid out } \\
\text { (10 mL/24 hours) }\end{array}$ & $410.17 \pm 374.16$ & $373.74 \pm 334.53$ & 0.004 \\
\hline AKI & $521(6.3 \%)$ & 39 (4\%) & 0.005 \\
\hline AKI stages & & & 0.029 \\
\hline
\end{tabular}


Table 1 Continued

\begin{tabular}{cll}
\hline Clinical features & $\begin{array}{l}\text { Without parecoxib } \\
(\mathbf{n = 8 2 7 3 )}\end{array}$ & $\begin{array}{l}\text { With parecoxib } \\
(\mathbf{n = 9 7 3 )}\end{array}$ \\
\hline 0 & 93.7 & 96 \\
\hline 1 & 4.5 & 2.6 \\
\hline 2 & 1 & 0.7 \\
\hline 3 & 0.7 & 0.7 \\
\hline
\end{tabular}

Data are expressed as the number of patients (\%) or mean \pm SD. AKI stages (outcome of postoperative AKI was divided into four groups: stage 0 , no AKI; stage 1, AKI grade 1; stage 2, AKI grade 2 and stage 3 , AKI grade 3).

ACEI, ACE inhibitors; AKI, acute kidney injury; ARB, angiotensin receptor blockers; ASA, American Society of Anesthesiologist; BMI, body mass index; CCB, calcium-channel blockers; eGFR, estimated glomerular filtration rate.

for potential confounders in multivariable regression models. To further validate these results in a number of specific populations that may influence the incidence of AKI. The sensitivity test was performed in the following four different subgroups: eGFR $<90 \mathrm{~mL} / \mathrm{min} \cdot 1.73 / \mathrm{m}^{2}$, non-smoker, blood loss $<1000 \mathrm{~mL}$ and non-hypotension. The results of the classification variable are expressed as OR or 'beta' and $95 \%$ CI; a p $<0.05$ indicated a statistically significant difference.

\section{RESULTS}

Of the 108198 records identified, those of 9246 patients were included in the analysis (figure 1). Reasons for excluding patients were age $<18$ or $>60$ years $(n=4783)$, ASA grade VI $(n=13)$, regional anaesthesia administrated by a surgeon $(n=12054)$, cardiac surgery $(n=387)$, urological surgery including kidney transplantation $(\mathrm{n}=3589)$, liver transplantation $(n=107)$, no recorded preoperative or postoperative creatinine data $(n=73093)$, no recorded covariate data such as routine blood panel or infusion volume $(n=4114)$, preoperative CKD $(n=472)$ and administration of parecoxib doses $>80 \mathrm{mg}(\mathrm{n}=340)$.

\section{Acute kidney injury}

The incidence of postoperative AKI was $6.06 \%$ (560/9246). In the AKI group, the probability of admission to the ICU and mortality was $10.18 \%$ and $4.64 \%$, respectively (online supplemental table 1 ).

There were no differences in age, BMI, and angiotensin receptor blockers (ARBs) use among patients with and without AKI (online supplemental table 1). Significant differences between patients with AKI and without AKI are shown in online supplemental table 1 (all $\mathrm{p}<0.05)$.

\section{Parecoxib}

Parecoxib was used in $10.5 \%(973 / 9246)$ of patients (table 1).

The incidence of AKI was lower in the parecoxibadministered group (4\%) than in the group without parecoxib $(6.3 \%, \mathrm{p}=0.005)$. There was no difference in age, BMI, eGFR, sex, smoking, alcohol consumption, presence of diabetes mellitus, use of ACE inhibitors (ACEIs), ARBs or diuretics, ASA grade, the incidence of intraoperative erythrocyte transfusion and intraoperative hypotension, and use of vasoactive drugs between patients treated with and without parecoxib (table 1). Significant differences between patients treated with and without parecoxib are shown in table $1($ all $\mathrm{p}<0.05)$.

\section{Univariable analysis}

The factors are shown by the univariable analysis to influence AKI development in patients aged 18-60 years who underwent non-cardiac surgery are listed in table 2.

In the univariable analysis, male sex, smoking, alcohol consumption, anaemia, hypertension, diabetes mellitus, ACEI use, calcium channel blocker (CCB) use, diuretic use, ASA grade III-V, emergency, surgical grade 4, duration of the operation, the incidence of intraoperative hypotension and erythrocyte transfusion and amount of blood loss were independently associated with an increased risk of postoperative AKI (table 2).

Parecoxib (OR 0.62; 95\% CI 0.45 to $0.87, \mathrm{p}=0.005$ ), eGFR (OR $0.96 ; 95 \%$ CI 0.96 to $0.97, \mathrm{p}<0.0001$ ), nongeneral anaesthesia (OR 0.44; 95\% CI 0.30 to 0.65 , $\mathrm{p}<0.0001)$ and vasoactive drug use (OR 0.06; 95\% CI 0.03 to $0.09, \mathrm{p}<0.0001)$ were independently associated with a decreased risk of postoperative AKI (table 2). Age (OR $1.01 ; 95 \%$ CI 1.00 to $1.02, \mathrm{p}=0.0737$ ), BMI (OR 0.98; $95 \%$ CI 0.95 to $1.00, \mathrm{p}=0.0396$ ) and ARB use (OR 1.76; $95 \%$ CI 0.98 to $3.14, \mathrm{p}=0.0570$ ) were not correlated with AKI (table 2).

\section{Multivariable regression analysis}

The occurrence of postoperative AKI or AKI stages was regarded as a dependent variable, and the administration of parecoxib, an independent variable when we performed the stepwise regression analysis (table 3).

The risk adjustment models were constructed using logistic stepwise regression. After adjusting for these interference factors, parecoxib was still independently associated with postoperative AKI (OR 0.61; 95\% CI 0.43 to 0.87 , model 4 in table 3 ) or different postoperative AKI stages (OR -0.03 ; $95 \%$ CI -0.05 to -0.00 , model 4 in table 3).

\section{Sensitivity analysis}

Table 4 presents the association between postoperative AKI and parecoxib in the subgroups of eGFR $<90 \mathrm{~mL} /$ 
Table 2 Univariable analysis of AKI

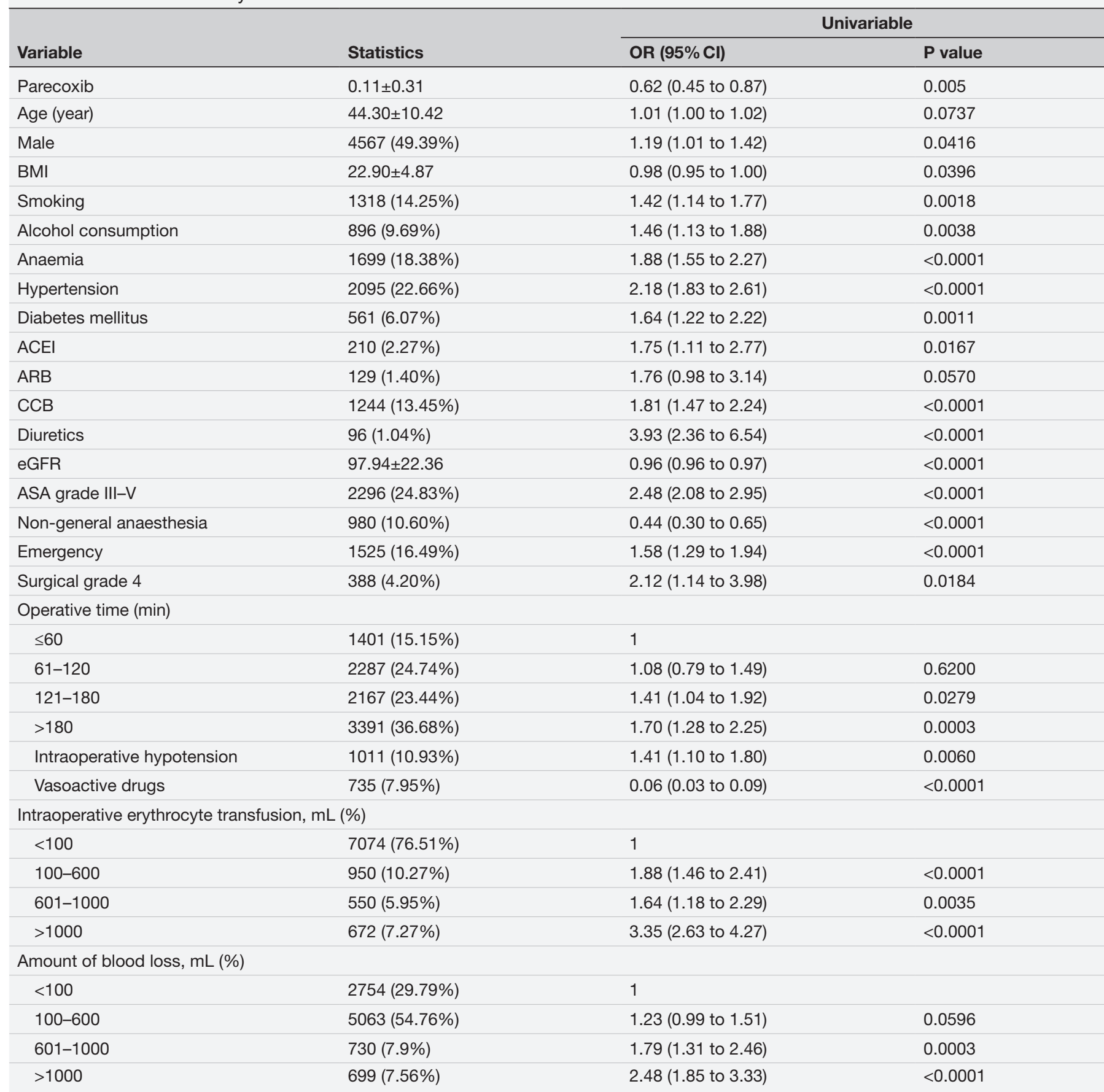

ACEI, ACE inhibitors; AKI, acute kidney injury; ARB, angiotensin receptor blockers; ASA, American Society of Anesthesiologists; BMI, body mass index; CCB, calcium-channel blockers; ;eGFR, estimate glomerular filtration rate.

$\min \cdot 1.73 / \mathrm{m}^{2}$, non-smokers, blood loss $<1000 \mathrm{~mL}$ and intraoperative non-hypotension.

For patients with an eGFR $<90 \mathrm{~mL} / \mathrm{min} \cdot 1.73 / \mathrm{m}^{2}$ or who were non-smokers, single-dose parecoxib (40 mg or $80 \mathrm{mg}$ ) was associated with a lower incidence of postoperative AKI (table 4). Similar results were obtained with the adjusted models. Postoperative AKI risk also reduced in patients with blood loss $<1000 \mathrm{~mL}$ (OR $0.55 ; 95 \%$ CI 0.37 to 0.83 ) and non-hypotension (OR $0.57 ; 95 \%$ CI 0.38 to 0.84$)$.

\section{DISCUSSION}

According to the surgery type and AKI diagnostic criteria, the incidence of postoperative AKI ranges from $1.0 \%$ to $31 \%,{ }^{13-15}$ and our study revealed an incidence of $6.06 \%$ in the study population of patients aged 18-60 years who underwent non-cardiac surgery. The incidence was similar to that in the recently published data by Nishimoto $(6 \%$, non-cardiac surgery; mean age, 63 years).${ }^{16}$ In our study, the univariable analysis identified male sex, smoking, alcohol consumption, anaemia, hypertension, diabetes 
Table 3 OR of postoperative AKI associated with parecoxib

\begin{tabular}{|c|c|c|c|c|}
\hline & $\begin{array}{l}\text { Model } 1 \\
\text { OR }(95 \% \mathrm{Cl}) \mathrm{p} \text { value }\end{array}$ & $\begin{array}{l}\text { Model } 2 \\
\text { OR }(95 \% \mathrm{Cl}) \mathrm{p} \text { value }\end{array}$ & $\begin{array}{l}\text { Model } 3 \\
\text { OR }(95 \% \mathrm{Cl}) \mathrm{p} \text { value }\end{array}$ & $\begin{array}{l}\text { Model } 4 \\
\text { OR }(95 \% \mathrm{Cl}) \mathrm{p} \text { value }\end{array}$ \\
\hline AKI & $\begin{array}{l}0.62(0.45 \text { to } 0.87) \\
0.0050\end{array}$ & $\begin{array}{l}0.64(0.46 \text { to } 0.90) \\
0.0096\end{array}$ & $\begin{array}{l}0.63(0.44 \text { to } 0.89) \\
0.0095\end{array}$ & $\begin{array}{l}0.61(0.43 \text { to } 0.87) \\
0.0069\end{array}$ \\
\hline AKI stages & $\begin{array}{l}-0.02(-0.05 \text { to } 0.00) \\
0.0627\end{array}$ & $\begin{array}{l}-0.02(-0.05 \text { to }-0.00) \\
0.0792\end{array}$ & $\begin{array}{l}-0.02(-0.05 \text { to }-0.00) \\
0.0517\end{array}$ & $\begin{array}{l}-0.03(-0.05 \text { to }-0.00) \\
0.0236\end{array}$ \\
\hline
\end{tabular}

AKI stages (outcome of postoperative AKI was divided into four groups: stage 0 , no AKI; stage 1, AKI grade 1; stage 2, AKI grade 2 and stage 3, AKI grade 3).

Model 1: non-adjusted.

Model 2: adjusted for age, sex, BMI, smoking, alcohol consumption, anaemia, hypertension, diabetes mellitus, ACEI, CCB, diuretics, ASA, anaesthesia method, emergency, surgical grade, amount of fluid infusion and out, intraoperative erythrocyte transfusion and amount of blood loss.

Model 3: model 2 plus ARB, eGFR and operative time.

Model 4: model 3 plus intraoperative hypotension and vasoactive drugs.

ACEI, ACE inhibitor; AKI, acute kidney injury; ARB, angiotensin receptor blocker; ASA, American Society of Anesthesiologists; BMI, body mass index; $C C B$, calcium channel blocker; eGFR, estimate glomerular filtration rate.

mellitus, ACEI use, CCB use, diuretic use, eGFR, ASA grade III-V, anaesthesia mode, emergency, surgical grade 4 , duration of the operation (>120 min), the incidence of intraoperative hypotension, intraoperative erythrocyte transfusion $(>100 \mathrm{~mL})$, amount of blood loss $(>600 \mathrm{~mL})$ and vasoactive drug use to be associated with AKI, some of which are similar to previously published data by Mathis $e t$ $a l$ and Cho et al. ${ }^{17} 18$

However, age and BMI did not correlate with AKI in our study, which is inconsistent with the findings from Wang $e$ t $a l$ s studies. ${ }^{19}$ This discrepancy can be explained by the difference in mean age and BMI between the studies, which were both lower in our study population. The results of the sensitivity analysis suggested that single-dose (40 $\mathrm{mg}$ or $80 \mathrm{mg}$ ) parecoxib might have potential protective effects against postoperative AKI in differentially ranked AKI. eGFR $<90 \mathrm{~mL} / \mathrm{min} \cdot 1.73 / \mathrm{m}^{2}$ represented the population with preoperative glomerular filtration impairment, while non-hypertension and bloodloss $<1000 \mathrm{~mL}$, represented people with relatively stable intraoperative circulation and relatively good renal perfusion pressure. The subgroup analysis showed parecoxib might reduce the AKI risk in these patients.

Numerous studies have investigated the association between NSAIDs and AKI. ${ }^{10}{ }^{20}$ An updated Cochrane systematic review and meta-analysis published by Bell et $a l$ indicated that NSAIDs have uncertain effects on the rate of AKI and may slightly increase serum creatinine in patients with normal kidney function following surgery. ${ }^{20}$ In another meta-analysis (Ungprasert $e t a l$ ), a significant risk of AKI was observed with most traditional NSAIDs but not with two COX-2-specific inhibitors (rofecoxib and celecoxib). ${ }^{10} \mathrm{~A}$ pooled analysis of 28 randomised clinical trials investigating the safety of parecoxib for the

Table 4 Sensitivity analysis of the association between postoperative AKI and parecoxib

\begin{tabular}{|c|c|c|c|c|c|}
\hline & Without & $\begin{array}{l}\text { Model } 1 \\
\text { OR }(95 \% \mathrm{Cl}) \mathrm{p} \\
\text { value }\end{array}$ & $\begin{array}{l}\text { Model } 2 \\
\text { OR }(95 \% \mathrm{Cl}) \text { p value }\end{array}$ & $\begin{array}{l}\text { Model } 3 \\
\text { OR }(95 \% \mathrm{Cl}) \text { p value }\end{array}$ & $\begin{array}{l}\text { Model } 4 \\
\text { OR }(95 \% \mathrm{Cl}) \text { p value }\end{array}$ \\
\hline & parecoxib & \multicolumn{4}{|c|}{ Parecoxib } \\
\hline eGFR $<90$ & 1 & $\begin{array}{l}0.49(0.31 \text { to } 0.79) \\
0.0032\end{array}$ & $\begin{array}{l}0.54 \text { (0.33 to } 0.87) \\
0.0119\end{array}$ & $\begin{array}{l}0.50(0.30 \text { to } 0.84) \\
0.0084\end{array}$ & $\begin{array}{l}0.49(0.29 \text { to } 0.82) \\
0.0065\end{array}$ \\
\hline Non-smoker & 1 & $\begin{array}{l}0.57(0.39 \text { to } 0.84) \\
0.0040\end{array}$ & $\begin{array}{l}0.56(0.37 \text { to } 0.84) \\
0.0046\end{array}$ & $\begin{array}{l}0.56 \text { (0.38 to } 0.84) \\
0.0052\end{array}$ & $\begin{array}{l}0.55 \text { (0.37 to } 0.83) \\
0.0043\end{array}$ \\
\hline Non-hypotension & 1 & $\begin{array}{l}0.60(0.42 \text { to } 0.87) \\
0.0064\end{array}$ & $\begin{array}{l}0.60(0.42 \text { to } 0.87) \\
0.0077\end{array}$ & $\begin{array}{l}0.57(0.38 \text { to } 0.84) \\
0.0050\end{array}$ & \\
\hline
\end{tabular}

Model 1: non-adjusted.

Model 2: adjusted for age, sex, BMI, smoking, alcohol consumption, anaemia, hypertension, diabetes mellitus, ACEI, CCB, diuretics, ASA, anaesthesia method, emergency, surgical grade, amount of fluid infusion and out, intraoperative erythrocyte transfusion and amount of blood loss.

Model 3: model 2 plus ARB, eGFR and operative time

Model 4: model 3 plus intraoperative hypotension and vasoactive drugs.

ACEI, ACE inhibitor; AKI, acute kidney injury; ARB, angiotensin receptor blocker; ASA, American Society of Anesthesiologists; BMI, body mass index; CCB, calcium channel blocker; eGFR, estimate glomerular filtration rate. 
management of postoperative pain showed that its associated risk of renal failure and impairment was $1 \%$, similar to that with the placebo $(0.9 \%) .^{21}$

However, our study indicated that intraoperative singledose parecoxib (40 $\mathrm{mg}$ or $80 \mathrm{mg}$ ) might provide potential protective effects against postoperative AKI in patients aged 18-60 years who underwent non-cardiac surgery. Moreover, this is not the first time a renoprotective effect has been postulated for parecoxib. For example, the study of Takaku et al also showed that a single-dose of parecoxib $(20 \mathrm{mg} / \mathrm{kg})$ reduced tubular renal injury and serum inflammatory cytokines level (interleukin (IL)-1 $\alpha$, IL- $\beta$, IL6, and tumour necrosis factor- $\alpha$ ) in an ischaemic rat model. ${ }^{22}$ Moreover, several animal studies(Takaku $e t$ $a l$, Feitoza et al, Feitoza et al, Candelario-Jalil et al) have suggested that pretreatment with COX-2 inhibitors improved outcomes in function and histology in not only the kidney but also other organs after ischaemia. ${ }^{22-25}$ To the best of our knowledge, this is the first clinical report to suggest that single-dose ( $40 \mathrm{mg}$ or $80 \mathrm{mg}$ ) parecoxib may be renoprotective in patients aged 18-60 years who underwent non-cardiac surgery.

The mechanism by which parecoxib decreases the risk of postoperative AKI is unknown. However, one possible underlying mechanism is likely related to inflammation. A previous study by Murashima et al showed that inflammation is a predictor of postoperative AKI and a mediator of increased mortality after AKI in non-cardiac surgery. ${ }^{26}$ However, perioperative parecoxib reduced local and systemic inflammatory cytokines postoperatively. ${ }^{27} 28$ Another possible mechanism is associated with haemodynamic change. COX-1 contributes to controlling renal GFR, whereas COX-2 is involved in sodium and water excretion. ${ }^{7}$ COX-2 inhibitors are associated with mild hypertension owing to modest sodium retention in the first few days of therapy. ${ }^{29}$ The renoprotective mechanism of parecoxib may be related to its anti-inflammatory effects and sodium regulation.

Our study had some limitations that are worth mentioning. First, this was a retrospective single-centre observational study; thus, it may have had some selection bias. Second, the timing of the serum creatinine measurement was based on clinical discretion; thus, it may vary with different doctors. Third, we simply chose patients aged 18-60 years who underwent non-cardiac surgery as the target to research. Fourthly, due to the nature of the retrospective study, some unknown or unmeasured confounders, and those excluded patients who had missing data may interfere with the outcomes. Therefore, our results should be extrapolated cautiously.

\section{CONCLUSIONS}

In conclusion, in non-cardiac surgery patients, a single dose of parecoxib (40 $\mathrm{mg}$ or $80 \mathrm{mg}$ ) may be associated with a modest reduction of postoperative AKI in those aged 18-60 years. However, these short-term effects may not represent the benefit of this drug in the long term.
Furthermore, more comprehensive studies are needed to confirm the effects of parecoxib on the risk of postoperative AKI.

\section{Author affiliations}

${ }^{1}$ Department of Anesthesiology, Central South University Third Xiangya Hospital, Changsha, Hunan, People's Republic of China

${ }^{2}$ Hunan University College of Computer Science and Electronic Engineering, Changsha, Hunan, People's Republic of China

${ }^{3}$ Institute of Microelectronics pf Chinese Academy of Sciences, Beijing, People's Republic of China

${ }^{4}$ Operation center, Central South University Third Xiangya Hospital, Changsha, People's Republic of China

Acknowledgements We thank Dr Xing Liu for the technical consultation.

Contributors Y-ZT helped in designing the study, analysing and interpreting the data, and drafting and revising the manuscript. PZ and YL helped in collecting, analysing and interpreting the data, and drafting and revising the manuscript. ZQ, $\mathrm{HZ}$ and $\mathrm{BL}$ helped in analysing and interpreting the data. WO helped in supervising, funding acquisition and drafting and revising the manuscript. DL helped in designing the study, analysing and interpreting the data and drafting and revising the manuscript.

Funding This work was supported by the National Key R\&D Programme of China (grant number 2018YFC2001800), Project of Health and Health Commission of Hunan Province (grant number 20201802), Hunan Province Key Laboratory Project (grant number 2018TP1009) and the Research and Innovation Funds from Xiangya Bigdata Foundation of Central South University.

Competing interests None declared.

Patient consent for publication Not required.

Ethics approval This study was approved by the ethics committee of the third Xiangya hospital of Central South University (2020S264). Because of the observational nature of the study, informed consent was waived.

Provenance and peer review Not commissioned; externally peer reviewed.

Data availability statement Data are available on reasonable request. The data used and analyzed in this study are available from the corresponding author on reasonable request.

Supplemental material This content has been supplied by the author(s). It has not been vetted by BMJ Publishing Group Limited (BMJ) and may not have been peer-reviewed. Any opinions or recommendations discussed are solely those of the author(s) and are not endorsed by BMJ. BMJ disclaims all liability and responsibility arising from any reliance placed on the content. Where the content includes any translated material, BMJ does not warrant the accuracy and reliability of the translations (including but not limited to local regulations, clinical guidelines, terminology, drug names and drug dosages), and is not responsible for any error and/or omissions arising from translation and adaptation or otherwise.

Open access This is an open access article distributed in accordance with the Creative Commons Attribution Non Commercial (CC BY-NC 4.0) license, which permits others to distribute, remix, adapt, build upon this work non-commercially, and license their derivative works on different terms, provided the original work is properly cited, appropriate credit is given, any changes made indicated, and the use is non-commercial. See: http://creativecommons.org/licenses/by-nc/4.0/.

\section{ORCID iDs}

Yong-Zhong Tang http://orcid.org/0000-0003-3746-360X

Dan Li http://orcid.org/0000-0002-8613-1006

\section{REFERENCES}

1 Romagnoli S, Ricci Z. Postoperative acute kidney injury. Minerva Anestesiol 2015;81:684-96.

2 Ortega-Loubon C, Fernández-Molina M, Carrascal-Hinojal Y, et al. Cardiac surgery-associated acute kidney injury. Ann Card Anaesth 2016;19:687-98.

3 Bell S, Ross VC, Zealley KA, et al. Management of post-operative acute kidney injury. QJM 2017;110:695-700.

4 Iyigun M, Aykut G, Tosun M, et al. Perioperative risk factors of acute kidney injury after non-cardiac surgery: a multicenter, prospective, 
observational study in patients with low grade American Society of Anesthesiologists physical status. Am J Surg 2019;218:457-61.

5 Turan A, Cohen B, Adegboye J, et al. Mild acute kidney injury after noncardiac surgery is associated with long-term renal dysfunction: a retrospective cohort study. Anesthesiology 2020;132:1053-61.

6 Cuniberti B, Odore R, Barbero R, et al. In vitro and ex vivo pharmacodynamics of selected non-steroidal anti-inflammatory drugs in equine whole blood. Vet $J$ 2012;191:327-33.

7 Lucas GNC, Leitão ACC, Alencar RL, et al. Pathophysiological aspects of nephropathy caused by non-steroidal anti-inflammatory drugs. J Bras Nefrol 2019;41:124-30.

8 Mitchell JA, Warner TD. Cox isoforms in the cardiovascular system: understanding the activities of non-steroidal anti-inflammatory drugs. Nat Rev Drug Discov 2006;5:75-86.

9 Sriperumbuduri S, Hiremath S. The case for cautious consumption: NSAIDs in chronic kidney disease. Curr Opin Nephrol Hypertens 2019;28:163-70.

10 Ungprasert P, Cheungpasitporn W, Crowson CS, et al. Individual non-steroidal anti-inflammatory drugs and risk of acute kidney injury: a systematic review and meta-analysis of observational studies. Eur J Intern Med 2015;26:285-91.

11 Amabile CM, Spencer AP. Parecoxib for parenteral analgesia in postsurgical patients. Ann Pharmacother 2004;38:882-6.

12 Khwaja A. KDIGO clinical practice guidelines for acute kidney injury. Nephron Clin Pract 2012;120:c179-84.

13 Kim M, Brady JE, Li G. Variations in the risk of acute kidney injury across intraabdominal surgery procedures. Anesth Analg 2014;119:1121-32.

14 Biteker M, Dayan A, Tekkeșin Ahmet İlker, et al. Incidence, risk factors, and outcomes of perioperative acute kidney injury in noncardiac and nonvascular surgery. Am J Surg 2014;207:53-9.

15 Vaara ST, Bellomo R. Postoperative renal dysfunction after noncardiac surgery. Curr Opin Crit Care 2017;23:440-6.

16 Nishimoto M, Murashima M, Kokubu M, et al. Positive association between intra-operative fluid balance and post-operative acute kidney injury in non-cardiac surgery: the NARA-AKI cohort study. $J$ Nephrol 2020;33:561-8.

17 Mathis MR, Naik BI, Freundlich RE, et al. Preoperative risk and the association between hypotension and postoperative acute kidney injury. Anesthesiology 2020;132:461-75.

18 Cho E, Kim S-C, Kim M-G, et al. The incidence and risk factors of acute kidney injury after hepatobiliary surgery: a prospective observational study. BMC Nephrol 2014;15:169.
19 Wang J, Yu W, Zhai G, et al. Independent risk factors for postoperative AKI and the impact of the AKI on 30-day postoperative outcomes in patients with type $A$ acute aortic dissection: an updated meta-analysis and meta-regression. $J$ Thorac Dis 2018;10:2590-8.

20 Bell S, Rennie T, Marwick CA, et al. Effects of peri-operative nonsteroidal anti-inflammatory drugs on post-operative kidney function for adults with normal kidney function. Cochrane Database Syst Rev 2018;11:CD011274.

21 Schug SA, Parsons B, Li C, et al. The safety profile of parecoxib for the treatment of postoperative pain: a pooled analysis of 28 randomized, double-blind, placebo-controlled clinical trials and a review of over 10 years of postauthorization data. $J$ Pain Res 2017; 10:2451-9.

22 Takaku M, da Silva AC, Iritsu NI, et al. Effects of a single dose of parecoxib on inflammatory response and ischemic tubular injury caused by hemorrhagic shock in rats. Pain Res Treat 2018;2018:1-8.

23 Feitoza CQ, Câmara NOS, Pinheiro HS, et al. Cyclooxygenase 1 and/or 2 blockade ameliorates the renal tissue damage triggered by ischemia and reperfusion injury. Int Immunopharmacol 2005;5:79-84.

24 Feitoza CQ, Sanders H, Cenedeze M, et al. Pretreatment with indomethacin protects from acute renal failure following ischemiareperfusion injury. Transplant Proc 2002;34:2979-80.

25 Candelario-Jalil E, González-Falcón A, García-Cabrera M, et al. PostIschaemic treatment with the cyclooxygenase-2 inhibitor nimesulide reduces blood-brain barrier disruption and leukocyte infiltration following transient focal cerebral ischaemia in rats. $J$ Neurochem 2007;100:1108-20.

26 Murashima M, Nishimoto M, Kokubu M, et al. Inflammation as a predictor of acute kidney injury and mediator of higher mortality after acute kidney injury in non-cardiac surgery. Sci Rep 2019;9:20260.

27 Chong SJ, Wong YC, Wu J, et al. Parecoxib reduces systemic inflammation and acute lung injury in burned animals with delayed fluid resuscitation. Int J Inflam 2014;2014:1-11.

28 Zhu Y, Wang S, Wu H, et al. Effect of perioperative parecoxib on postoperative pain and local inflammation factors PGE2 and IL-6 for total knee arthroplasty: a randomized, double-blind, placebocontrolled study. Eur J Orthop Surg Traumatol 2014;24:395-401.

29 Hegazy R, Alashhab M, Amin M. Cardiorenal effects of newer NSAIDs (celecoxib) versus classic NSAIDs (ibuprofen) in patients with arthritis. J Toxicol 2011;2011:1-8. 